\title{
The Influence of Parental Autonomy-Support on Cognitive Self-Reliance of Senior Secondary School Students
}

\author{
Awopetu Anna V. \\ Department of Early Childhood Care and Education, School of Education, \\ College of Education, Ikere-Ekiti, Ekiti State, Nigeria \\ annawopetu@rambler.ru \\ Omoteso Bonke A. \\ Department of Educational Foundations and Counselling, Faculty of Education, \\ Obafemi Awolowo University, Ile-Ife, Nigeria \\ baomoteso@yahoo.co.uk
}

\section{Doi:10.5901/jesr.2014.v4n6p27}

\begin{abstract}
The study investigated the parental autonomy-support given to senior secondary school students in Ekiti State, Nigeria. It examined the level of parental autonomy-support to senior secondary school students; it found the influence of parental autonomy-support on students' cognitive self-reliance. It also investigated the difference between fathers' and mothers' levels of autonomy-support given to the students; and examined if the fathers' and mothers' autonomy-support would determine students' level of cognitive self-reliance. Four hundred and fifty (450) students and their parents were purposively selected from four public secondary schools in two Local Government Areas of Ekiti State. Two LGAs were selected, using simple random sampling technique, while two schools from each LGA were selected purposively because only co-educational public secondary schools with no boarding facilities were used for the study. The results of the data analyses showed that $35.3 \%$ of the parents of senior secondary school students demonstrated high level of parental autonomy-support to their children. Parental autonomy-support had no significant influence on cognitive self-reliance of the students $(\chi 2=5.89, p>0.05)$; there was no significant difference between fathers' and mothers' levels of parental autonomy-support to the students $(t=0.299, p>$ 0.05); mothers' autonomy-support had a stronger influence on adolescents' level of cognitive self-reliance when compared with the fathers' autonomy-support $(\beta=0.824 ; t=17.610, p<.05$ and $\beta=0.149 ; t=3.188, p<0.05)$. The study concluded that parental autonomy-support could not be a factor in cognitive self-reliance of students.
\end{abstract}

Keywords: Parental Autonomy-Support, Cognitive Self-Reliance, Adolescence

\section{Introduction}

Africa, having an awareness of the importance of technological progress and creativity, is gradually transforming from a traditional continent with taboos and superstitions to a dynamic and modern society. Nonetheless, the degree of creativity, independence and self-reliance in African students of $21^{\text {st }}$ century is yet to be satisfactory (Oluwatelure \& Oloruntegbe, 2010). In Nigeria for example, many parents want their adolescent children to be independent and be able to make decisions themselves. However, in the course of the researchers' interaction with secondary school students in some parts of Nigeria, it was discovered that many of them lacked independent thinking and were not confident. They depended on their parents for many things including school homework, assignments, choice of career and higher institutions. It was also observed that in many cases, parents were taking a leading role in doing things for their secondary school children (Awopetu \& Omoteso, 2014). A UK-trained Nigerian Recruitment Consultant based and practising in Lagos, Mrs Funmi Wale-Adegbite, in her interview on BBC - World Service Programme identified the root of such a situation and called it "My children will not suffer what I suffered" syndrome. In her opinion, Nigerian youths are not exposed to challenges; they do not know how to work hard and Nigerian parents deliberately deny their adolescent children more opportunities to explore the world so that they can stand alone (Wale-Adegbite, 2011).

All perspectives on the development of self-reliant youths emphasise the large spectrum of outcomes that may follow from a lack of appropriate support for autonomy. Autonomy-support means that an individual in a position of authority takes the other's perspective, acknowledges the other's feelings, and provides the other with pertinent 
information and opportunities for choice, while minimising the use of pressures and demands (Deci \& Ryan, 1985).

According to Brauer (2011), autonomy-supportive parenting can be measured by three variables, which are:

(1) autonomy-supportive rule-setting;

(2) autonomy-supportive communication; and

(3) psychological autonomy-support.

This perspective emphasizes the multi-dimensional structure of parental autonomy-support and how it influences adolescents' development. In other words, rule-setting, communication and psychological autonomy-support play an important role in cognitive development of adolescents.

Reviewed literature indicated that parents of the adolescent students usually demonstrate support for their children's autonomy, encourage their independence and autonomous thoughts and actions (Demo \& Cox, 2000). Also, it was found that both parents respected their adolescent children autonomy by giving them opportunity to make independent decisions, by allowing them to set goals and have a right in taking family decisions (Ratelle, Larose, Guay \& Senecal, 2005). According to Tiller, Garrison, Cramer \& Tiller (2003), parenting may have more direct influence on children's social and emotional development rather than on cognitive development during adolescence.

In earlier works, it was suggested that the issue of parenting practices must be addressed from the gender perspective (Simons and Conger, 2007; Bean, Barber, \& Crane, 2006). For example, Simons and Conger (2007) stated that researchers often examined the parenting of mothers and assumed that fathers' parenting is the same as mothers'. Simons and Conger (2007), therefore, inferred that the conclusions made without including separate analyses for mothers and fathers could be speculative. Hence, it is necessary to understand that both parents are equally important and make use of separate analyses in research on parenting.

For the adolescents to be self-reliant, including cognitive self-reliance, they must learn to work on their own with the minimal help from their parents. Self-reliance helps to develop cognitive, intellectual and creative potentials. It influences the degree of understanding and quality of acquired knowledge, especially in adolescence.

Adolescents' self-reliance in everyday life is reflected in the academic domain. There are several research findings that confirmed low performance of Nigerian secondary school students in core subjects, limited opportunities for science laboratory experimentation and problem solving activities (Agboola \& Ajayi, 2011; Obidoa, 2006). Nigerian teachers often report that students do not demonstrate abilities of critical thinking, objectivity and persistence. In contrast, there are records of high level of academic achievement in secondary schools but school counsellors still complain about deficiency in personal management, creativity and adequate autonomy. Such outcomes diminish the quality of acquired knowledge and lead to manifestation of learning difficulties at the tertiary education level.

The construct "cognitive self-reliance" is often used to refer to a set of psycho-social characteristics such as personal independence, capacity to make decisions, self-evaluation skills, creativity and freedom from the constraints of dependence on others (Steinberg, 1990). Contemporary researchers are of the opinion that cognitive self-reliance starts manifesting in the period of early adolescence when an adolescent experiences transition from primary to secondary level, which requires adaptation and adjustment to a new environment. The majority of Nigerian parents do not, however, expect their teenage children to be fully independent in their decisions. They justify such an attitude by the fact that teenagers are not cognitively prepared to confront mature circumstances. In the opinion of many parents, they are ready to support their children's desire for autonomy when those children have reached a certain level of cognitive development and social maturity and demonstrate ability to take responsibility for their actions and thoughts.

It is a well known fact that Nigerian secondary school day students spend more time in the school and out of home than with their families. Still, parents encourage them to attend summer schools, extra lessons, coaching classes and in addition parents employ home teachers. Yet the examination results of students are poor. What could be responsible for this? Some experts (Shindel, 2006; Tella \& Tella, 2003) believed that schools do not teach students how to become autonomous and self-reliant in life. At the same time, teachers strongly believe that their efforts will be in vain if they are left to do everything with no parental contributions. Ogunleye, Omirin and Balogun (2013) stated that Ekiti State secondary schools' teachers were being consistently credited as trying their best to have good students' outcomes. It implies that poor students' achievements could not be attributed to teachers alone. The authors further suggested that there should be a shift in paradigm to the parents and, therefore, more emphases should be placed on parental role in adolescents' developmental outcomes. Parental involvement does not actually mean extra control and unnecessary monitoring. There must be a balance in the autonomy-support given by parents to adolescents. Therefore, there is a need to determine to what degree parents have to be involved and be autonomy-supportive to provide adequate development of self-reliance.

The present situation in parental involvement adolescent children's upbringing in Ekiti State is not so encouraging. 
Nowadays, because of civilization, enculturation of Western life style and due to socio-economic situation in Nigeria, parents are destabilised and forced to shift their parental responsibilities to maids, teachers or boarding schools (Falana \& Bada, 2013). Therefore, children are left in the care of other adults, rather than of biological parents. Such children do not enjoy or are slightly deprived of physical, emotional and psychological support of parents. The other problems children are likely to face include cognitive deficits which may affect their cognitive self-reliance as well. Therefore, it is obvious that schools and teachers alone cannot handle the task of all-round child's development even if children spend more time in school than with their parents. These and related problems may not occur if at a certain period in life, a child receives enough attention from the parents, and has more opportunities to be independent at appropriate age and trained to be self-reliant.

\section{Statement of the Problem}

The construct "cognitive self-reliance" is often used to refer to a set of psychosocial characteristics such as personal independence, capacity to make decisions, self-evaluation skills, creativity and freedom from the constraints of dependence on others. In Nigeria, most senior secondary school students are not cognitively self-reliant. They depend mostly on parents when they need to set goals, make decisions or evaluate themselves. There is the need to investigate parents' autonomy-support and its influence on cognitive self-reliance of senior secondary school students.

\section{Purpose of the Study}

The study was conducted to:

(1) characterise the present situation on parental autonomy-support in Ekiti State, Nigeria.

(2) identify the appropriate degree of freedom and autonomy-support parents must offer to their adolescent children who are yet to complete their secondary school stage of education.

\section{Research Question and Research Hypotheses}

One research question was asked to be answered and three hypotheses postulated to be tested.

Research Question

What is the level of parental autonomy-support given to senior secondary school students?

Research Hypotheses

1. Parental autonomy-support has no significant influence on cognitive self-reliance of senior secondary school students in Ekiti State.

2. There is no significant difference between fathers' and mothers' autonomy-support given to the students.

3. Fathers' autonomy-support and mothers' autonomy-support would not determine students' level of cognitive self-reliance.

\section{Methodology}

\subsection{Research Design, Population and Sample}

The study adopted the descriptive survey research design. The population for the study consisted of all students in senior secondary schools in Ekiti State and their parents. The sample size comprised 1,239 students and parents. From the two randomly selected Local Government Areas (LGAs) of Ekiti State, four public senior secondary schools were selected purposively. Purposive sampling technique was used because only co-educational public secondary schools with no boarding facilities were used for the study. Senior secondary school students who lived with their parents were purposively selected (through the interactions with the schools' counsellors, who helped to get necessary information from students' files). Also, in purposive selection of students, it was ensured that only students whose parents could understand the content of the questionnaire were selected (school counsellors assisted with the interviewing the selected students for the final sample). In total, 423 students and 816 parents (402 fathers and 414 mothers) participated in the study. 


\subsection{Research Instruments}

The students were asked to fill the "Student's Self-Reported Cognitive Self-Reliance Questionnaire" (SSRCSRQ). The instrument was developed using the works of Beckert (2007), Singh and Singh (1995) and Patel (1976) and was made up of two sections. Section A consisted of four items, which included demographic variables such as student's personal data (sex and class) and student's family characteristics (family structure and number of children in the family). The items on demographic variables were coded in line with the number of sub-groups within each item. Section B was made up of a 25-item scale, which was designed for the students to assess themselves on their cognitive self-reliance. Only subscales that were relevant to the present study were extracted and the original items were reworded to suit the Nigerian cultural setting. These items include among others, if students are independent in their decisions; if they plan by themselves all the steps to complete any project/assignment; if they need family members to approve their decisions; if they are confident in their decision-making abilities. The students were asked to rate their responses, using a four-point rating scale ranging as "Always", "Often", "Sometimes" and "Never".

The parents filled "Parental Autonomy-Support Questionnaire" (PASQ) which was made up of two sections. Section A was made up of demographic variables. It consisted of four items that related to parents' personal data. The items included family characteristics (structure, number of children in the family), parents' highest educational attainment, occupation and degree of religiosity. Degree of religiosity was determined by fathers' and mothers' responses to subitems of items 3c and 4c. The items were adapted from "The Religiosity Scale" (Valenzuela, Scully, \& Somma, 2009).

Section B comprised 20 items on parental autonomy-support for each parent to fill separately. This section was designed to gather information on the level of parental autonomy-support given to the child. The items for this section were adapted from "Perceptions of Parents Scale" (Luyckx, Soenens, Goossens, \& Vansteenkiste, 2007), "Parenting Measure Scale" (Steinberg et al., 1992) and "Parenting Styles and Dimensions Questionnaire" (Robinson, Mandleco, Olsen \& Hart (2001). The original items were mostly reconstructed and simplified for easy understanding by the respondents; some were dropped as not relevant for Nigerian parents. In purposive selection of the students, it was ensured that parents of selected students could understand the content of the questionnaire when it was read to them in English.

Parents were asked to rate the items on parental autonomy-support, using a four-point rating scale from "Strongly disagree" to "Strongly Agree". The respondents were required to identify only one option that best described their support for their child's autonomy.

The validity of the two instruments was carried out through consultations with the experts in the fields of Psychology of Education, Tests and Measurement and Psychology. The experts reviewed the instruments in terms of relevance to the subject-matter, coverage of the contents areas, appropriateness of language usage and clarity of purpose. The experts' judgements revealed that the two instruments had an adequate content validity.

Also, the instruments were tested for reliability. The Cronbach's Alpha and Guttmann reliability estimate of SSRCSRQ and PASQ were 0.725 and 0.756 , and 0.817 and 0.855 respectively. Both instruments were tested at the 0.05 level of significance. The reliability tests obtained from the instruments indicated that they had good internal consistency, which were adequate enough for the study.

With permissions from the principals of the sampled schools, questionnaires were administered on the participants during scheduled counselling classes by the researchers, four trained research assistants and the counsellors of the selected schools. It was also explained to the students that they had to take home the questionnaire and convince their parents to fill it in. The research assistants and counsellors appealed to the students to return the parents' questionnaires to school the next day. In some instances, parents' questionnaires were returned after three-four days after special efforts were employed. A total of 450 questionnaires were originally designed for the administration. However, the researchers were able to retrieve questionnaires from 423 students and 816 parents. The others were either not well completed or could not be retrieved. All students' copies of the questionnaires were returned immediately after administration.

\section{Results}

Research Question 1: What is the level of parental autonomy-support given to senior secondary school students?

To answer this question, parents' responses to items of part 1 and part 2 (for father and mother respectively) of "Parental Autonomy-Support Questionnaire" (PASQ) were scored and the scores were used to determine the level of autonomy-support that fathers and mothers gave to their children. Parents, with regard to the level of their autonomy- 
support, were rated as having "High", Moderate" and "Low" levels of parental autonomy-support. Further analysis was done to determine each student's combined parental autonomy-support. This was done by adding both parents' autonomy-support scores. When the scores were combined, the minimum and maximum scores obtained were 60 and 160 and a mean value $(\bar{X}=108.85, \mathrm{SD}=14.63)$ was obtained. On this scale, scores ranged between 60 and 94 indicated a low level of parental autonomy-support, while scores between 95 and 122 indicated moderate parental autonomy-support level, and scores between 123 and 160 implied high level of parental autonomy support. Table 1 presents the result.

Table 1: Parental Autonomy-Support Levels

\begin{tabular}{|c|c|c|c|c|}
\hline & & Frequency & Percent & Cumulative Percent \\
\hline \multirow{4}{*}{ Valid } & High & 136 & 31.8 & 35.3 \\
\hline & Moderate & 132 & 31.1 & 69.9 \\
\hline & Low & 115 & 27.1 & \multirow{4}{*}{100.0} \\
\hline & Total & 383 & 89.9 & \\
\hline No response & System & 40 & 10.1 & \\
\hline \multicolumn{2}{|c|}{ Total } & 423 & 100.0 & \\
\hline
\end{tabular}

Table 1 shows that only 383 fathers' and mothers' responses to items of PASQ can be synchronised. It is also shown that $35.3 \%$ of the parents had a high level of autonomy-support for their children, while $34.6 \%$ had a moderate autonomysupport level, and $30.1 \%$ of the parents had low level of parental autonomy-support. From the above, it was revealed that parents exhibited mostly high level of autonomy-support (35.3\%).

Hypothesis 1: Parental autonomy-support has no significant influence on cognitive self-reliance of senior secondary school students in Ekiti State.

To test this hypothesis, the influence of fathers' and mothers' parental autonomy-support on the students' level of cognitive self-reliance was first determined separately. It was then followed with the combined influence of the two parents' parental autonomy-support on the cognitive self-reliance of students. The relationship between two variables was determined by using chi-square inferential statistics. The results of cross tabulation are presented in Table 2.

Table 2: The Influence of Parental Autonomy-Support on Students' Cognitive Self-Reliance

\begin{tabular}{|c|c|c|c|c|c|c|}
\hline \multirow[t]{2}{*}{ Parental Autonomy-Support Levels } & \multicolumn{3}{|c|}{ Students' Cognitive Self-Reliance Levels } & \multirow{2}{*}{$\chi^{2}$} & \multirow{2}{*}{$d f$} & \multirow{2}{*}{$\mathrm{p}$} \\
\hline & High & Average & Low & & & \\
\hline High & $48(41.7 \%)$ & $64(34.4 \%)$ & $23(28.4 \%)$ & \multirow{3}{*}{5.89} & \multirow{3}{*}{4} & \multirow{3}{*}{$>0.05^{\star \star}$} \\
\hline Moderate & $31(27.0 \%)$ & $67(36.0 \%)$ & $34(42.0 \%)$ & & & \\
\hline Low & $36(31.3 \%)$ & $55(29.6 \%)$ & $24(29.6 \%)$ & & & \\
\hline
\end{tabular}

${ }^{\star \star}$ Not significant at $p>0.05$

Results as presented in Table 2 show that while the parents of $41.7 \%$ of students that had high level of cognitive selfreliance also had high level of parental autonomy-support. The parents of remaining $27.0 \%$ and $31.3 \%$ of the students had moderate and low autonomy-support respectively. The Table also shows that parents of $36.0 \%$ and $34.4 \%$ of the average cognitively self-reliant students had moderate and high autonomy-support respectively. The chi-square value $\left(\chi^{2}\right.$ $=5.89, p>0.05)$ implies that parents' autonomy-support has no significant influence on the students' cognitive selfreliance. Therefore, the null hypothesis is not rejected. students.

Hypothesis 2: There is no significant difference between fathers' and mothers' autonomy-support given to the

To test this hypothesis, the difference in fathers' and mothers' parental-autonomy support questionnaire scores was investigated with the use of independent t-test. The result is as presented in Table 3. 
Table 3: t-test Showing the Difference between Fathers' and Mothers' Autonomy-Support to the Students

\begin{tabular}{|l|c|c|c|c|c|c|}
\hline \multicolumn{1}{|c|}{ Students' Parents } & $\mathrm{N}$ & $\bar{X}$ & $\mathrm{SD}$ & $\mathrm{t}$ & $\mathrm{df}$ & $\mathrm{p}$ \\
\hline Father & 4402 & 54.4204 & 7.89456 & \multirow{2}{*}{0.229} & \multirow{2}{*}{8144} & $>0.05^{\star *}$ \\
\hline Mother & 4414 & 54.2560 & 7.80868 & & & \\
\hline
\end{tabular}

** Not significant at $p>0.05$

The result as presented in Table 3 shows that the means of parental autonomy-support scores for fathers and mothers respectively are $\bar{X}=54.42$ and $\bar{X}=54.25$. The obtained $\mathrm{t}$-test value ( $\mathrm{t}=0.299, \mathrm{p}>0.05$ ) is an indication that the difference between the means of autonomy-support given to the students by fathers and mothers is not significant. Therefore, the hypothesis that stated that there is no significant difference between fathers' and mothers' autonomysupport to the students is not rejected.

Hypothesis 3: Fathers' autonomy-support and mothers' autonomy-support would not determine students' level of cognitive self-reliance.

To test how each of the independent variables (fathers' autonomy-support and mothers' autonomy-support) could relatively determine senior secondary school students' cognitive self-reliance, the data collected on fathers' and mothers' autonomy-support were coded and correlated with the dependent variable (students' cognitive self-reliance). The data were analysed using multiple regression. The results are presented in Table 4.

Table 4: Beta Coefficients and t-ratio for Relative Contributions of Independent Variables to the Prediction of the Dependent Variable

\begin{tabular}{|l|c|c|c|c|c|c|c|c|}
\hline \multirow{2}{*}{ Model } & \multicolumn{2}{|c|}{ Unstandardised Coefficients } & Standardised Coefficients & \multirow{2}{*}{$\mathrm{t}$} & \multicolumn{3}{|c|}{$\mathrm{p}$} & \multicolumn{3}{|c|}{ Correlations } \\
\cline { 2 - 4 } \cline { 7 - 9 } & $\beta$ & Std. Error & Beta & & & Zero-order & Partial & Part \\
\hline (Constant) & 96.383 & 1.959 & & 49.188 & $<0.05^{\star}$ & & & \\
\hline Mothers' Autonomy Support & -.668 & .038 & -.824 & -17.610 & $<0.05^{\star}$ & -.723 & -.663 & -.604 \\
\hline Fathers' Autonomy Support & .123 & .039 & .149 & 3.188 & $<0.05^{\star}$ & -.411 & .158 & .109 \\
\hline
\end{tabular}

a. Dependent Variable: cognitive total

*Significant at $p<0.05$

From Table 4, it could be observed that the independent variables as a whole have a significant relationship on the dependent variable with the constant unstandardised coefficient $(\beta=96.383 ; t=49.188, p<0.05)$. The results also show that mothers' autonomy-support received a stronger weight in the model, when compared with the fathers' autonomysupport $(\beta=0.824 ; t=17.610, p<.05$ and $\beta=0.149 ; t=3.188, p<0.05)$. However, with the sizeable correlation between the predictors, the unique variance explained by each of the variables indexed by the squared semipartial correlations was quite low. Inspection of the structure coefficients suggested that the fathers' autonomy-support was also a strong predictor of students' cognitive self-reliance.

\section{Discussion}

The answer on the Research Question suggests that parents of the participated students demonstrated all three levels of parental autonomy-support. What was most interesting to discover was that the distribution was in relatively equal proportion. However, majority of the parents were reported as highly autonomy-supportive, followed by moderate and low levels. Thus, the present finding is consistent with the findings by Demo \& Cox (2000) and Ratelle et al. (2005) that parents of the adolescent students demonstrated support for their children's autonomy, encouraged their independence and autonomous thoughts and actions. Also, the finding revealed that both parents respected their adolescent children autonomy by giving them opportunity to make independent decisions, by allowing them to set goals and have a right in taking family decisions. This finding corroborated the study carried by Brauer (2011), which upheld a fact that autonomysupportive parenting is very important during adolescence and that parental autonomy-support is associated with desirable child outcomes. In addition, it was also stated that degree of autonomy-support mostly depends upon the stage of adolescence examined. The above mentioned statement is also related to the present study, where difference 
between scores on high and moderate levels of parental autonomy-support was not much. Such a result could be also explained by students' age as well as by students' social status, from the perspective of Nigerian cultural setting. It means that it is a Nigerian belief that a secondary school child who still lives with his/her parents even regardless of his/her age must have a certain degree of dependence and submissiveness. Such parents' attitude might be responsible for the relatively high percentage on low level of parental autonomy-support as well as for the little difference in scores on high and moderate levels of parental autonomy-support.

The results obtained in testing Null Hypothesis 1 revealed that parental autonomy-support had no significant influence on cognitive self-reliance of senior secondary school students in Ekiti State. This implies that parental autonomy-support might not be counted as a major factor influencing students' cognitive self-reliance. This finding was in line with the work of Tiller et al. (2003) which suggested that parenting may have more direct influence on children's social and emotional development rather than on cognitive development during adolescence. One possible reason that the present findings revealed non-significance of parental autonomy-support on adolescents' cognitive self-reliance could be that the relationship of adolescents and their parents tend to change and other factors such as peer relationships may have a stronger influence on them.

It is evident from the result of Null Hypothesis 2 that there was no significant difference between fathers' and mothers' autonomy-support to the students. Such a finding supported earlier works of Bean et al. (2006), Milevsky et al. (2006) and Silva et al. (2007) where parenting was measured separately for each parent. However, studies conducted by Margolin et al. (2001) and McHale et al. (2002) demonstrated the need to conceptualise parenting as interdependent concept where relationship between mothers' and fathers' parenting practices were presented as an important contribution to children's functioning, perhaps more important than the individual contributions of mothers' or fathers' parenting styles. Hence, it is necessary to understand that both parents are equally important and have a role to play in supporting their children autonomy and self-reliance. The necessity to conceptualise parenting style from gender perspectives was as well suggested by Silva et al. (2007) who was of opinion that students' cognitive skills could be improved with the interventions that address maternal and paternal parenting styles separately. However, in the study of Simons and Conger (2007), it was stated that researchers often examined the parenting of mothers and assumed that fathers' parenting is the same as mothers'. This study also agreed with the findings of Lindsey and Mize (2001) that fathers' involvement and influence in children's lives is on increase in recent times. This trend must be noted and upheld by promoting importance of paternal parenting among both parents of adolescents. Thus, the present study agreed with the earlier works, which found the importance of addressing the issue of parenting practices from the gender perspective. Hence, it is necessary to understand that both parents are equally important and have a role to play in supporting their children's autonomy and self-reliance.

Findings from Hypothesis 3 indicated that mothers' autonomy support had a stronger weight in predicting the level of students' cognitive self-reliance when compared with the fathers' autonomy-support. However, fathers' autonomysupport was also qualified as a strong predictor. Thus, this result, which says that both parents can relatively predict students' level of cognitive self-reliance, confirmed another finding of this study, which says, that there was no significant difference between fathers' and mothers' levels of autonomy-support.

\section{Conclusion}

The study established that although parents of senior secondary school students demonstrated mostly a high level of parental autonomy-support to their children, the influence of parental autonomy-support on cognitive self-reliance of the students was not significant. This might be because the relationship of adolescents and their parents tend to change and other factors, for example, students' personal characteristics, family structure or peer relationships may have a stronger influence on them. The study also concluded that mothers' autonomy support had a stronger weight in predicting the level of students' cognitive self-reliance when compared with the fathers' autonomy-support.

\section{Recommendations}

An adequate and appropriate level of cognitive self-reliance and autonomy in adolescent students is an essential component of their personality. This component must be formed at appropriate time in adolescence period of one's development through the influence of both parents' support for autonomy and through the impact of many other factors such as teacher's autonomy-support, relationship with peers, extended family influence. They may directly and indirectly modify one's cognitive skills in order to improve adolescents' self-reliance and independence in cognitive domain. As 
parents interact with their children, they should maintain a balance between autonomy granting and monitoring which will enhance and encourage the child's need for autonomy. By providing adolescents with the opportunities to make choices and live with the results of their choices, parents can help children to become wise decision-makers and cognitively selfreliant.

Parents should be made to realise that they play most important roles in upbringing their own children. They should understand that school alone cannot be effective in building adequate personality in their children. Hence, it is recommended that parents should have enough understanding and knowledge about their parental roles so that they will be able contribute their own quota for all-round development of senior secondary school students. It implies that parents should understand the essence of allowing their children to pass through certain degree of hardship in life and not only protecting them from challenges and difficulties for the sake of "not suffering as we suffered when we were young". Parents need to employ effective parental practices that will enhance their adolescent children self-reliance. They should offer an adequate level of autonomy-support their children need from them at appropriate period to be able improve on their level of cognitive self-reliance. Fathers especially should be educated about importance of paternal input and be encouraged to contribute more, directly and indirectly, to autonomy development in their adolescent children. To achieve that, school administrators and academic staff should work in conjunction with parents because it is very important for them to be educated and guided by professionals for effective discharge of parental functions and responsibilities.

It is also recommended that every senior secondary school student should put into practice all elements that constitute cognitive self-reliance. Furthermore, it is very important for every adolescent to reach adequate level of autonomy and self-reliance before entering into adulthood. Thus, students should be allowed to participate in family decisions, school activities that promote independent thoughts, sense of autonomy and self-reliance. Students should be trained to generate their own planning, self-monitor and evaluate their goals. Schools, from their own end, should promote importance of managerial skills, critical and creative thinking as a part of Life Skills Education, which should be repeatedly practiced. Such a methodology will lead to a certain mastery and application of such skills to real life situations and will eventually enable individuals to deal effectively with the demands and challenges of everyday life. Inclusion of life skills training will promote cognitive competences and reduce behavioural problems among adolescents as well. Students should be exposed to entrepreneurial training, which may enhance their independent thinking, decisionmaking skills and, therefore, improve their level of cognitive self-reliance.

Finally, it is very important that governments of all levels are cognizant of the effects and roles of parental autonomy-support as regards adolescents' level of cognitive self-reliance. Therefore, governments are advised to reflect those issues while developing curriculum, organising workshops and seminars for parents or in-service training for concerned school staff.

\section{References}

Agboola, O. S., \& Ajayi, A. E. (2011). A comparative analysis of two methods of teaching environment related concepts in senior secondary school chemistry. Ife Journal of Educational1Studies, 14(1), 57-64.

Awopetu, A.V., \& Omoteso, B. O. (2014). An examination of cognitive self-reliance of senior secondary school students. Researchjournali's Journal of Education, Vol.2 № 2, February. pg. 1 - 12.

Bean, R. A., Barber, B. K., \& Crane, R. D. (2006). Parental support, behavioral control, and psychological control among African American youth. Journal of Family Issues, 27, 1335-1355.

Beckert, T. (2007). Cognitive autonomy and self-evaluation in adolescence: a conceptual investigation and instrument development. North American Journal of Psychology, 9(3), 579-594.

Brauer, J. R. (2011). Autonomy-supportive parenting and adolescent delinquency. (Unpublished Doctoral dissertation). North Carolina State University, Raleigh, North Carolina, USA.

Deci, E. L., \& Ryan, R. M. (1985). Intrinsic motivation and self-determination in human behaviour. New York: Plenum.

Demo, D. H., \& Cox, M. J. (2000). Families with young children: A review of research in the 1990s. Journal of Marriage and the Family, 62, 867-895.

Falana, B. A., \& Bada, F. O. (2013). Social, economic and educational implications of parental separation on upbringing of school children in Ekiti State. Global Advanced Research Journal of Peace, Gender and Development Studies, 2 (2), 021-025.

Lindsey, E. W., \& Mize, J. (2001). Interparental agreement, parent-child responsiveness, and children's peer competence. Family Relations: Journal of Applied Family \& Child Studies, 50, 348-354.

Luyckx, K., Soenens, B., Goossens, L., \& Vansteenkiste, M. (2007). Parenting, identity formation, and college adjustment: A mediation model with longitudinal data. Identity: An International Journal of Theory and Research, 7(4), 309-330.

Margolin, G., Gordis, E. B., \& John, R. S. (2001). Coparenting: A link between marital conflict and parenting in two-parent families. Journal of Family Psychology, 15, 3-21.

McHale, J., Khazan, I., Erera, P., Rotman, T., DeCourcey, W., \& McConnell, M. (2002). Coparenting in diverse family systems. In M. 
Bornstein (Ed.), Handbook of parenting. Vol.

Milevsky, A., Schlechter, M., Netter, S., \& Keehn, D. (2006). Maternal and paternal parenting styles in adolescents: Associations with self-esteem, depression, and life satisfaction.

Obidoa, M. (2006). Enhancing the instructional supervisory skills of principals of secondary schools. Principals Year Book. A publication of All Nigerian Conference of Principals of Secondary Schools (ANCOPSS). Nsukka, Nigeria. Moke Social Publishers.

Ogunleye, A. J., Omirin, M. S. \& Balogun, S. K. (2013). Males, females, parenting styles, and academic performance of secondary school students in Ekiti state Nigeria: an empirical investigation. Elixir Human Res. Mgm., 56, 13626-13629.

Oluwatelure, T. A. \& Oloruntegbe, K. O. (2010) Effects of parental involvement on students' attitude and performance in science. African Journal of Microbiology Research, 4(1), 1-9.

Patel, B. V. (1976). Manual for study habits inventory, Agra Psychological Research cell. Tiwari Kothi, Belanganj: Agra.

Ratelle, C. F., Larose, S., Guay, F., \& Senecal, C. (2005). Perceptions of parental involvement and support as predictors of college students' persistence in a science curriculum. Journal of Family Psychology, 19, 268-293.

Robinson, C. C., Mandleco, B., Frost Olsen, S., \& Hart, C. H. (2001). The parenting styles and dimensions questionnaire (PSDQ). In B. F. Perlmutter, J. Touliatos, \& G. W. Holden (Eds.), Handbook of family measurement techniques. Vol. 2: Instruments and index. Thousand Oaks, CA: Sage.

Shindel, M. (2006). Inverting the achievement pyramid. Principal Leadership (Middle School Ed.), 6(8), 28-30.

Silva, M., Dorso, E., Azhar, A., \& Renk, K. (2007). The relationship among parenting styles experienced during childhood, anxiety, motivation, and academic success in college students. Journal of College Student Retention: Research, Theory \& Practice, 9 , 149-167.

Simons, L. G., \& Conger, R. D. (2007). Linking mother-father differences in parenting to a typology of family parenting styles and adolescent outcomes. Journal of Family Issues, 28, 212-241.

Singh, R. K., \& Singh, A. K. (1995). Study habits of the advantaged and disadvantaged college students. Indian Psy. Rev., 44(9-10), 3340.

Steinberg, L. (1990). Autonomy, conflict, and harmony in the family relationship. In S. S. Feldman, \& G. R. Elliott (Eds.), At the threshold: The developing adolescent. Cambridge, MA: Harvard University Press.

Steinberg, L., Lamborn, S.D., Dornbusch, S.M., \& Darling, N. (1992). Impact of parenting practices on adolescent achievement: Authoritative parenting, school involvement, and encouragement to succeed. Child Development, 63, 1266-1281.

Tella, A. \& Tella, A. (2003). Parental involvement, home background, and school environment as determinants of academic achievement of secondary school students in Osun State, Nigeria. African Journal of Cross-Cultural psychology and Sport Facilitation, 5, (2), 42-48.

Tiller, A. E., Garrison, B., Cramer K, Tiller, V. (2003). The influence of parenting styles on children's cognitive development. Undergrad Res J Hum Sci., 2, 1-21.

Valenzuela, J. S., Scully, T. R., \& Somma, N. (2009). "Social and political effects of religiosity and religious identities in Latin America" Comparative Politics, 40(1), 1-20.

Wale-Adegbite, F. (2011) Over parenting by Nigerians. Retrieved from http:// bbc.co.uk/news/world-africa-14201223/ 
ISSN 2239-978X

ISSN 2240-0524
Journal of Educational and Social Research MCSER Publishing, Rome-Italy
Vol. 4 No. 6 September 2014 